\title{
Benign retropneumoperitoneum developed after endoscopic sphincterotomy and large balloon dilation of biliary sphincter for removal of large biliary stones: a case report
} Panagiotis Katsinelos ${ }^{1}$, Grigoris Chatzimavroudis*1, Ioannis Pilpilidis ${ }^{1}$, Christos Zavos ${ }^{2}$, Georgia Lazaraki ${ }^{1}$, Dimitris Tzilves ${ }^{1}$, George Paroutoglou ${ }^{1}$ and Jannis Kountouras ${ }^{2}$

\author{
Address: ${ }^{1}$ Department of Endoscopy and Motility Unit, Central Hospital, Thessaloniki, Greece and ${ }^{2}$ Department of Gastroenterology, Second \\ Department of Internal Medicine, Ippokration Hospital, Aristotle University of Thessaloniki, Thessaloniki, Greece \\ Email: Panagiotis Katsinelos - pk@yahoo.gr; Grigoris Chatzimavroudis* - gchatzimav@yahoo.gr; Ioannis Pilpilidis - ip@yahoo.gr; \\ Christos Zavos - czavos@hotmail.com; Georgia Lazaraki -gl@yahoo.gr; Dimitris Tzilves - dt@yahoo.gr; \\ George Paroutoglou -gparout@yahoo.gr; Jannis Kountouras - jannis@med.auth.gr \\ * Corresponding author
}

Published: 28 October 2008

Cases Journal 2008, 1:279 doi:10.1 186/1757-1626-1-279

This article is available from: http://www.casesjournal.com/content/I/I/279

(c) 2008 Katsinelos et al; licensee BioMed Central Ltd.

This is an Open Access article distributed under the terms of the Creative Commons Attribution License (http://creativecommons.org/licenses/by/2.0), which permits unrestricted use, distribution, and reproduction in any medium, provided the original work is properly cited.
Received: 8 October 2008

Accepted: 28 October 2008

\begin{abstract}
Biliary endoscopic sphincterotomy (ES) followed by biliary orifice dilation (BOD) with largediameter balloons (> $12 \mathrm{~mm}$ ) is a relative new technique for extraction of large biliary stones. However, the safety and the potential complications of this combined technique are not known yet. We present a patient who developed benign retroperitoneum after ES plus BOD with largediameter balloon for removal of a large biliary stone, which was successfully treated conservatively. To the best of our knowledge this is the first report of such a complication after introduction of this method to clinical practice.
\end{abstract}

\section{Background}

Biliary endoscopic sphincterotomy (ES) and stone extraction are considered as a standard therapy for treatment of biliary duct stones $[1,2]$. However, removal of large bile duct stones can be challenging in certain situations, such as after gastric bypass surgery or in the presence of periampullary diverticulum, stones located centrally to strictures and impacted stones $[3,4]$. The introduction by Ersoz et al [5] of ES followed by biliary orifice dilation (BOD) with large-diameter balloons (> $12 \mathrm{~mm}$ ) for extraction of large biliary stones was rapidly adopted with enthusiasm by other biliary endoscopists $[3,6,7]$. However, the safety and the potential complications of this new combined technique are not known yet.
We present a patient who developed benign retroperitoneum after ES plus BOD with large-diameter balloon (12 $\mathrm{mm}$ in diameter) for removal of a large biliary stone. To the best of our knowledge this is the first report of such a complication after introduction of this method to clinical practice.

\section{Case presentation}

A 78-year-old man with choledocholithiasis was referred to our department for ES and removal of biliary stones. On ERCP, the papilla was small without visible intramural course of common bile duct (CBD) in the duodenal wall. Cholangiography showed two large stones with diameters of 13 and $15 \mathrm{~mm}$, respectively, in a dilated CBD 
(diameter of $16 \mathrm{~mm}$ ). We performed the maximum possible, in length, ES, followed by mechanical lithotripsy and extraction of almost all the fragmented parts of stones. A relatively large piece of stone was impossible to be extracted by the balloon or captured by the lithotriptor. The biliary sphincter was dilated with a wire-guided balloon (CRE, Microvasive, USA) resulting in easy removal of the stone. On the afternoon the patient complained for a dull abdominal pain in the right upper quadrant but was afebrile without leucocytosis and there was no sign of peritoneal irrigation. An abdominal radiograph showed the presence of free air in the retroperitoneum (Fig. 1). An abdominal computed tomography (CT) revealed retropneumoperitoneum and aerobilia; however there was no evidence of contrast leakage from the bowel or biliary tract or retroperitoneal fluid collection. The patient was managed conservatively with intravenous fluid replacement, bowel rest and systemic antibiotics' administration. The abdominal pain was decreased gradually, while the patient continued to remain afebrile without leucocytosis. He was discharged 5 days after the procedure and a repeated abdominal $\mathrm{CT}$, performed one month later, demonstrated complete absorption of retroperitoneal air.

\section{Discussion}

ES with a large incision may be effective for extraction of large or difficult CBD stones; however, a large incision has a higher risk of perforation and probably a higher risk of bleeding $[8,9]$. Silent retroperitoneal air is not uncommon after ES and manipulation of papillary area [9-11]. Most of the symptomatic patients with retroperitoneal air are treated conservatively, but the risk of severe complications still exists [9-11]. Persistent abdominal pain and sys-

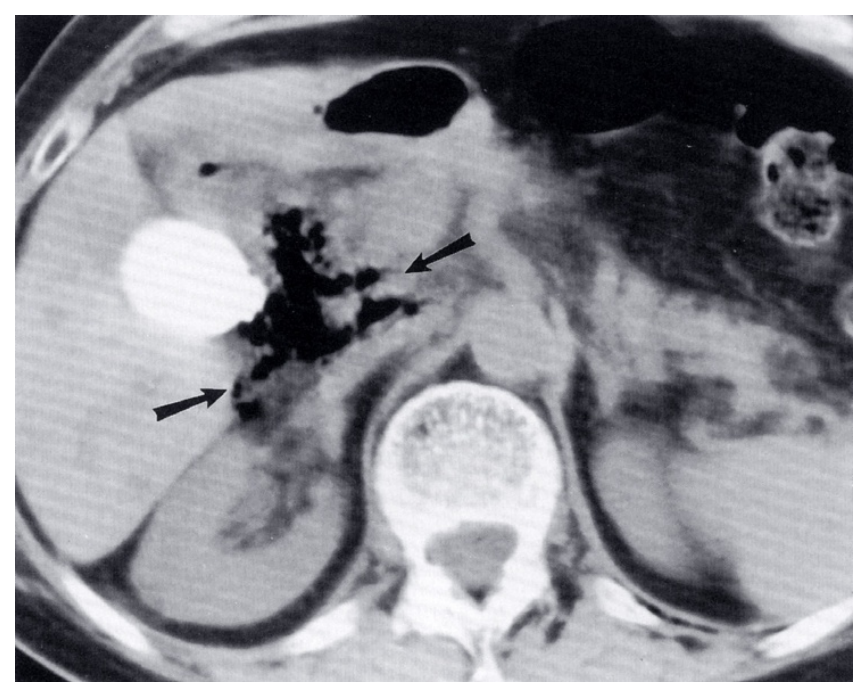

Figure I

Radiograph showing air (arrow) in the retroperitoneal space. temic toxic signs with leucocytosis should alert the management team, because continuous retroperitoneal leak of bile or duodenal juice leads to catastrophic results. Early surgical intervention, with extensive exploration, drainage and closure of the perforation, is generally indicated once severe retroperitoneal perforation is suspected [9-11].

To overcome the limitations of ES with large incision and endoscopic papillary balloon dilation (high rate of postprocedure pancreatitis and frequent use of mechanical lithotripsy), BOS after small or moderate ES has been advised as an effective method for retrieving large biliary stones without the use of mechanical lithotripsy $[3,6,7]$.

Patients in whom bile duct stones cannot be removed because of a tapered distal bile duct and patients with large, square or barrel-shaped stones would benefit from this procedure.

The most common complications of this procedure are mild cholangitis, pancreatitis, bleeding and perforation. Complications occurred in $15.5 \%$ of patients in one study [6], with most of them (10.3\%) being mild and self-limited. Moderately severe bleeding due to ES developed in three patients (5.2\%), all of whom recovered without the need for surgery. Perforation did not occur in any patient who underwent dilation with a large diameter balloon. Mild pancreatitis developed in two patients (3.4\%). Theoretically, the risk of pancreatitis by large balloon dilation after minimal or moderate sphincterotomy is less than balloon dilation alone. It is probable that after ES the force exerted by balloon dilation is directed mostly toward the common bile duct than the pancreatic orifice. Minimal or moderate ES before large balloon dilation might decrease the risk of pancreatitis as compared to dilation alone.

Overt perforations at the level of the major papilla after combined ES plus BOD have been rarely reported $[3,6,7]$, suggesting that initial sphincterotomy incision followed by the stretching and tearing effect of the forcible dilation is a safe way to provide the maximum exit for stones even when balloons of up to $18 \mathrm{~mm}$ are used. Endoscopic papillary dilation should be performed slowly with a large balloon (maximum of $20 \mathrm{~mm}$ in diameter) to match the size of the bile duct. The use of balloons having diameter larger than common bile duct size can lead to increased incidence of perforation. Approximately 1 minute of balloon dilation is considered sufficient. We believe that patients with distal CBD stenosis, a narrow CBD or nonvisible intramural course of CBD are at risk of perforation after balloon dilation. Therefore, it seems prudent to avoid excessive dilation in patients with these characteristics. 


\section{Conclusion}

The presence of air in the retroperitoneum is not always a detrimental complication of ES plus BOD and can be successfully treated conservatively in selected cases.

\section{Competing interests}

The authors declare that they have no competing interests.

\section{Authors' contributions}

PK performed the endoscopic sphincterotomy and was a major contributor in writing the manuscript. GC, IP and $\mathrm{CZ}$ analyzed and interpreted the patient data and were contributors in writing the manuscript. GL, DT and GP reviewed the relative literature. JK was major contributor in revising the manuscript critically for important intellectual content. All authors read and approved the final manuscript.

\section{Consent}

Written informed consent was obtained from the patient for publication of this case report and accompanying images. A copy of the written consent is available for review by the Editor-in-Chief of this journal.

\section{References}

I. Lauri A, Horton RC, Davidson BR, Burroughs AK, Dooley JS: Endoscopic extraction of bile duct stones: management related to stone size. Gut 1993, 34:1718-1721.

2. Cotton PB, Geenen JE, Sherman S, Cunningham JT, Howell DA, CarrLocke DL, Nickl NJ, Hawes RH, Lehman GA, Ferrari A, Slivka A, Lichtenstein DR, Baillie J, Jowell PS, Lail LM, Evangelou H, Bosco J], Hanson BL, Hoffman BJ, Rahaman SM, Male R: Endoscopic sphincterotomy for stones by experts is safe even in younger patients with normal ducts. Ann Surg 1998, 227:20I-204.

3. Toda N, Saito K, Wada R, Kawabe T, Shiratori Y, Mitsushima T, Omata $M$ : Endoscopic sphincterotomy and papillary balloon dilation for bile duct stones. Hepatogastroenterology 2005, 52:700-704.

4. Bergman J], Van Berkel AM, Bruno MJ, Fockens P, Rauws EA, Tijssen JG, Tytgat GN, Huibregtse K: A randomized trial of endoscopic balloon dilation and endoscopic sphincterotomy for removal of bile duct stones in patients with a prior Billroth II gastrectomy. Gastrointest Endosc 200I, 53:19-26.

5. Ersoz G, Tekesin O, Ozutemiz AO, Gunsar F: Biliary sphincterotomy plus dilation with a large balloon for bile duct. Gastrointest Endosc 2003, 57:156-159.

6. Hwang SJ, Kim YG, Lee KC: Endoscopic sphincterotomy plus endoscopic large balloon dilatation for large bile duct stones. Korean J Gastrointest Endosc 2006, 32: 181 - 189.

7. Minami A, Nomoto T, Moriyama T: Small sphincterotomy combined papillary dilatation with large balloon lithotripsy. Gastrointest Endosc 2005, 6 I:.

8. Freeman ML, Nelson DB, Sherman S, Haber GB, Herman ME, Dorsher PJ, Moore JP, Fennerty MB, Ryan ME, Shaw MJ, Lande JD, Pheley AM: Complications of endoscopic biliary sphincterotomy. $N$ Engl J Med 1996, 335:909-918.

9. Masci E, Toti G, Mariani A, Curioni S, Lomazzi A, Dinelli M, Minoli G, Crosta C, Comin U, Fertitta A, Prada A, Passoni GR, Testoni PA: Complications of diagnostic and therapeutic ERCP: a prospective multicenter study. Am J Gastroenterol 200I, 96:4I7-423.

10. Genzlinger JL, McPhee MS, Fisher JK, Jacob KM, Helzberg JH: Significance of retroperitoneal air after endoscopic retrograde cholangiopancreatography with sphincterotomy. Am J Gastroenterol 1999, 94:1267-1270.

II. Zissin R, Shapiro-Feinberg M, Oscadchy A, Pomeranz I, Leichtmann G, Novis B: Retroperitoneal perforation during endoscopic sphincterotomy: imaging finding. Abdom Imaging 2000, 25:279-282.

12. Chung RS, Sivak MV, Ferguson DR: Surgical decisions in the management of duodenal perforation complicating endoscopic sphincterotomy. Am J Surg 1993, 165:700-703.
Publish with Bio Med Central and every scientist can read your work free of charge

"BioMed Central will be the most significant development for disseminating the results of biomedical research in our lifetime. "

Sir Paul Nurse, Cancer Research UK

Your research papers will be:

- available free of charge to the entire biomedical community

- peer reviewed and published immediately upon acceptance

- cited in PubMed and archived on PubMed Central

- yours - you keep the copyright 